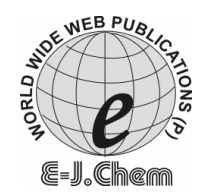

http://www.e-journals.net

ISSN: 0973-4945; CODEN ECJHAO

E-Journal of Chemistry

2008, 5(S1), 1015-1020

\title{
Synthesis, Characterization and Mechanical Evaluation of the Phenol-Formaldehyde Composites
}

\author{
B.S.KAITH and AASHISH CHAUHAN*
}

Dr. B. R. Ambedkar National Institute of Technology

(Deemed University), Jalandhar (Pb.) 144 011, India.

*aashishchauhan16@yahoo.co.in

Received 27 February 2008; Accepted 20 April 2008

\begin{abstract}
Phenol: formaldehyde ratio was varied in the synthesis of phenolformaldehyde resin and used to prepare the composites. These composites were then evaluated for their mechanical strength on the basis of tensile strength, compressive strength and wear resistance. Composite with better strength was characterized by IR, SEM, XRD, TGA/DTA and further studies were carried out for its physico-chemical and mechanical properties like viscosity, modulus of rupture (MOR), modulus of elasticity (MOE) and stress at the limit of proportionality (SP) etc.
\end{abstract}

Keywords: Mechanical properties, Strength, Modulus.

\section{Introduction}

Phenoplasts or the phenolic (PF) resins are produced by the condensation of phenol and formaldehyde. These were the first synthetic thermosets. They have a wide range of applications as lacquers and varnishes, molding compounds and laminates for wall panels and table tops etc. About $41 \%$ of the PF resins are used in plywood manufacture and about $14 \%$ in insulation ${ }^{1}$

Composites are the wonder materials, which after meeting the challenges of aerospace have cascaded down for catering to the domestic and industrial avenues. In the recent times many successful efforts have been made to prepare phenol-formaldehyde composites and to increase their mechanical potential by using different reinforcements like wood particle, hemp scotch, ${ }^{2}$ banana fiber ${ }^{3}$, cellulose fiber ${ }^{4}$ etc. Kaith et $a l^{5-7}$ reported the mechanical studies of the polymer composites reinforced with flax-g-copolymers.

The versatility of the phenol: formaldehyde resin based composites inspired to prepare its composites by altering the phenol: formaldehyde ratio and screening them on the basis of tensile strength, compressive strength and wear resistance. The best results thus obtained would then be further evaluated for their physico-chemical, mechnical $\&$ thermal behavior. 


\section{Experimental}

Phenol (S.D. Fine-Chem Ltd., India) and formaldehyde (CDH, India) were used as received. Composites were prepared in Compression Molding Machine (SANTECH India Ltd.). Libror AEG-220 (Shimadzu) electronic balance was used for weighing.

Wear resistance testing of the composites was carried out on the Wear \& Friction Monitor (DUCOM-TR-2OL), Compressive/Tensile strength, MOR, MOE and SP of the samples were tested on the Universal Testing Machine (HOUNSFIELD, H25KS). Curing and degasification were done on Compression Molding Machine (Santech India Ltd.).

Viscosity was tested on viscometer (Julabo ED). IR (Perkin Elmer) was used by forming $\mathrm{KBr}$ (Aldrich) pellets. XRD was done on Bruker D8 Advance on Zero background, PMMA holder. SEM was (LEO SERIES 435-25-20). TGA/DTA was done on thermal analyzer (Linseis, L81 11).

\section{Preparation of the resin}

Phenol-formaldehyde resin was prepared using the procedure as reported earlier ${ }^{5}$. Using, formaldehyde: phenol $(1: 0.25 ; 1.0: 0.5 ; 1.0: 0.75 ; 1.0: 1.0 ; 1.0: 1.25)$ in variable ratios, of their molecular weights, respectively. However, formation of the resin and composite thereafter with F: $\mathrm{P}$ in 1: 0.25 ratio was not feasible.

\section{Preparation of the composites}

The resin was degassed and poured into molds. The molds were coated inside with oleic acid to avoid adhesion of the mixture and for the ease in removal of the composites. The whole assembly was then placed inside the hot press and cured at $100^{\circ} \mathrm{C}$ and a pressure of $100 \mathrm{Kg} / \mathrm{cm}^{2}$ for $6-7$ hours was applied. Mean of three specimen samples were used as a result to determine the mechanical properties. The mechanical tests were conducted in ambient conditions.

Wear test, modulus of rupture, modulus of elasticity and stress at limit of proportionality wear resistance was calculated as per ASTM D 3702 and MOR, MOE and SP were tested on the basis of ASTM D 790 as per the method reported earlier ${ }^{8}$.

\section{Results and Discussion}

\section{Reaction mechanism}

In phenolic resin the major reactions involved are the addition to give methylol phenols, condensation of a methylol phenol and a phenol to give a methylene bridge, condensation of two methylol phenol and a phenol to give a methylene bridge, condensation to two methylol groups to give an ether bridges and decomposition of the ether bridges to methylene bridge and formaldehyde ${ }^{9}$. The mechanism used for the formation of the resole type PF resin involves the protonation of the carbonyl group of the formaldehyde followed by the electrophilic aromatic substitution at the ortho and para positions of the phenol. Phenol reacts with excess formaldehyde under basic conditions to form mono, di and tri methylolphenols. Phenol is present as resonance stabilized anion and substitution is exclusively at ortho, para. On heating the methylolphenols condense to give resole, which on further heating under basic or neutral or slightly acidic condition gives resite ${ }^{9,1}$.

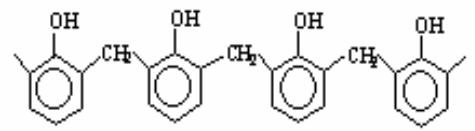

Resole 


\section{Mechanical screening of the P-F composite}

\section{Wear resistance}

As is evident from the Figure 1, that the phenol-formaldehyde resin formed in the ratio of 1: 0.75 of formaldehyde: phenol, had better wear resistance of $0.09,0.15$ and $0.2 \times 10^{-4} \mathrm{~g} / \mathrm{m}$ at all loads of 1, 2 and $3 \mathrm{Kg}$, respectively. On the other hand, formaldehyde: phenol in 1: 0.5 ratio showed $0.21,0.22$ and $0.25 \times 10^{-4} \mathrm{~g} / \mathrm{m}$; while $1: 1$ ratio showed $0.3,0.32,0.35 \times 10^{-4} \mathrm{~g} / \mathrm{m}$ and 1: 1.25 ratio had $0.42,0.44$ and $0.45 \times 10^{-4} \mathrm{~g} / \mathrm{m}$ wear resistance at 1,2 and $3 \mathrm{Kg}$, respectively. The weight loss in these composites mainly takes place due to abrasion and frictional heat generated due to sliding.

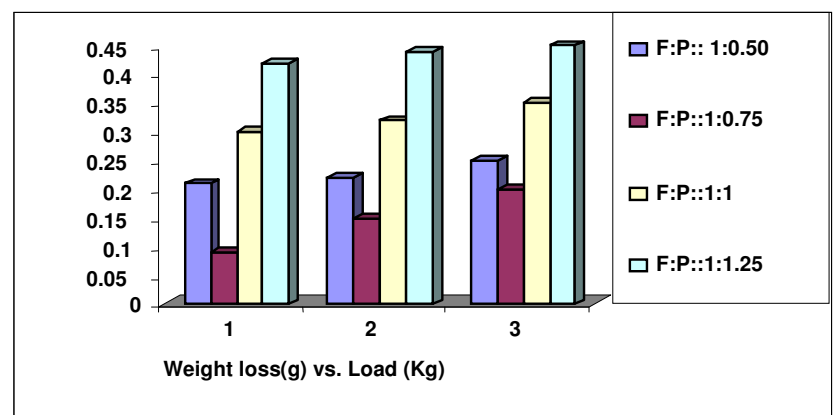

Figure 1. Effect of change in formaldehyde: phenol ratio on the wear rate of the phenolformaldehyde composites

\section{Tensile and Compressive strength}

As it is evident from the Figure 2, that the composite prepared by phenol-formaldehyde resin formed by formaldehyde: phenol in ratio of 1: 0.75 had better compressive and tensile strength of $780 \mathrm{~N}$ and $100 \mathrm{~N}$ with extension of 0.09 and $0.09 \mathrm{~mm}$, followed by the ratio 1 : 0.5 that had 725 and $90 \mathrm{~N}$ compressive and tensile strength with an extension of 0.8 and 0.7 $\mathrm{mm}, \mathrm{F}: \mathrm{P}:: 1: 1.5$ had 500 and $85 \mathrm{~N}$ force at an extension of 0.5 and $0.4 \mathrm{~mm}$ and $\mathrm{F}: \mathrm{P}$ with ratio 1: 1 had strength of 300 and $80 \mathrm{~N}$ with an extension of 0.7 and $0.3 \mathrm{~mm}$, respectively.

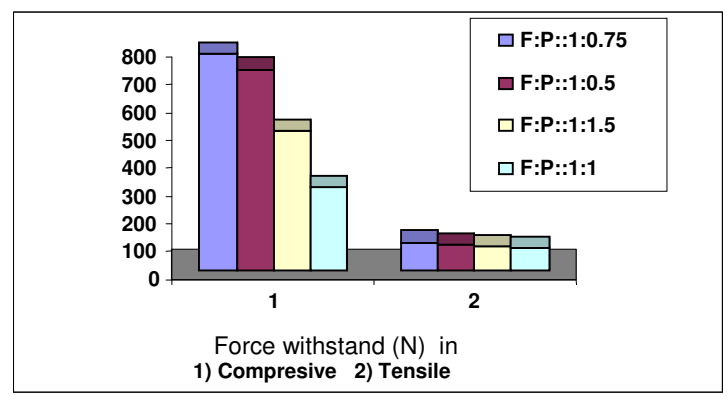

Figure 2. Effect of change in formaldehyde: phenol ratio on the tensile and compressive strength test of the phenol- formaldehyde composites

\section{Characterization}

From the above discussion, it is clear that the composites formed in the ratio 1.0: 0.75 of formaldehyde: phenol of their molecular weight had better mechanical properties. So, these composites were subjected to characterization. 


\section{Infra red analysis}

The IR spectrophotometer shows significant peaks at $3422 \mathrm{~cm}^{-1}$ due to $-\mathrm{OH}, 2920 \mathrm{~cm}^{-1}$ of $\mathrm{CH}_{2}$ stretch, $\mathrm{C}=\mathrm{C}$ stretch at $1609.9 \& 1508.6 \mathrm{~cm}^{-1}, 1475.5 \mathrm{~cm}^{-1}$ due to $\mathrm{CH}_{2}$ bend, $\mathrm{C}=\mathrm{C}$ bend at $1374.9 \mathrm{~cm}^{-1}$ and $1235 \mathrm{~cm}^{-1}$ due to $\mathrm{C}-\mathrm{O}$ stretch.

$X$-ray powder analysis

The X-ray powder diffractometer studies depict the d-values, continuous scan were taken between 3 to 40 at $2 \theta$ scale at $3 \mathrm{sec}$ scan speed and increment rate of 0.05 . Copper was the source of X-ray, Ni filter and scintillation counter mechanism. PMMA holder with zero background was used. Corundum was used to calibrate the system. The small crystal form of sample was subjected to analysis

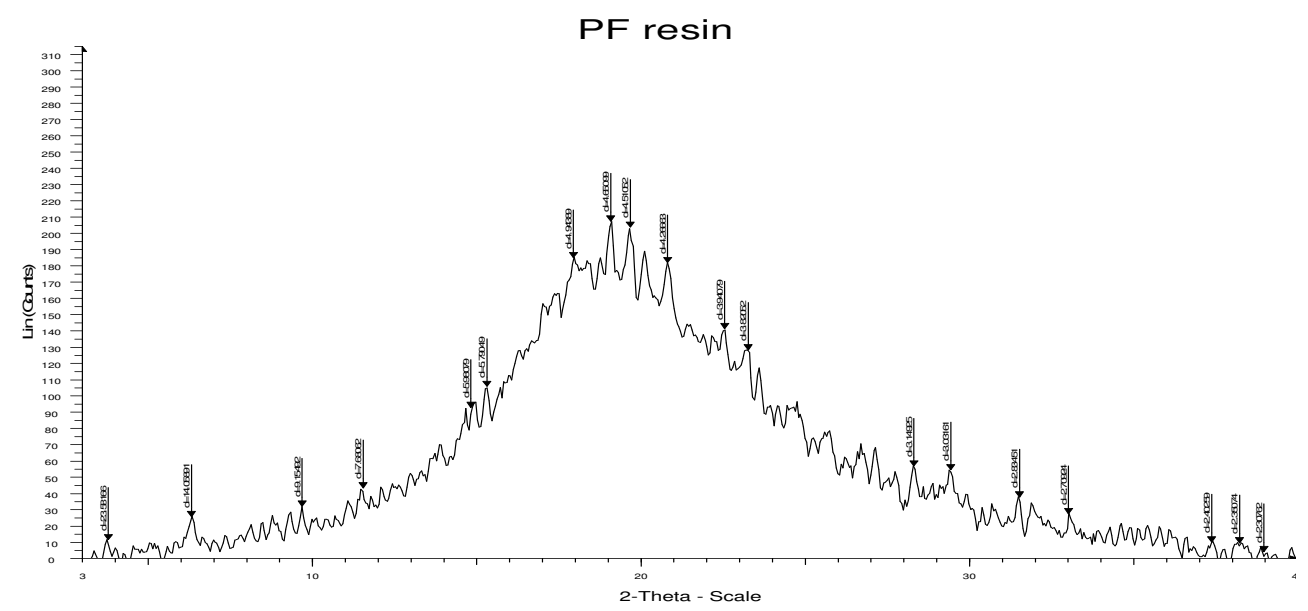

Figure 3. The XRD pattern of the P-F composite

\section{Scanning electron microscopy}

Since the composite had non conducting behavior so, they it was gold plated to have an impact. The Figure 4 clearly shows the well packed smooth surface of the composite.

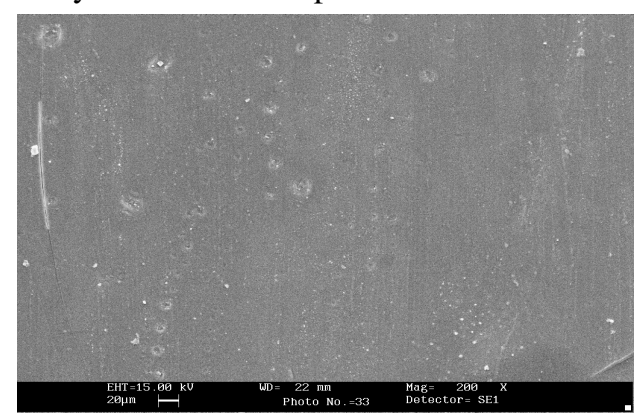

Figure 4. The P-F resin

\section{Physico-thermal, mechanical evaluation}

The formaldehyde: phenol in 1: 0.75 after being characterized were subjected to study their physical, thermal and mechanical behavior. 


\section{Viscosity and the $\mathrm{pH}$}

The viscosity of the resin was tested at different temperatures as it varies with the change in temperature as shown in Table 1 .

Table 1. The Viscosity of the P-F resin at different temperatures.

\begin{tabular}{ccc}
\hline Sr. No. & Temperature ${ }^{\circ} \mathrm{C}$ & Viscosity, Centipoise \\
\hline 1 & 40 & 120 \\
2 & 50 & 100 \\
3 & 60 & 90 \\
4 & 70 & 110 \\
5 & 80 & 150 \\
\hline
\end{tabular}

The $\mathrm{pH}$ of the resin was found to be 8.5 .

\section{Thermal study}

The each sample of weight $6.0 \mathrm{mg}$ was taken into the silica crucible for TGA / DTA analysis in air with temperature ranging from 50 to $1000^{\circ} \mathrm{C}$. The heating rate of the sample was $10^{\circ} \mathrm{C}$ per min and scanned for $60 \mathrm{mins}$. Air was taken as the reference for zero and the results, Delta-M (mg) $v s$. temperature $\left({ }^{\circ} \mathrm{C}\right)$ in case of TGA and DTA signal $(\mu \mathrm{V}) v s$. temperature $\left({ }^{\circ} \mathrm{C}\right)$ in case of DTA, were obtained.

The degradation occurs in various forms as deacetylation, dehydration, decarboxylation and chain scissions etc. The TGA /DTA results as shown in Table 2 depicts the high initial and final decomposition temperature i.e. IDT and FDT which signifies the higher thermal stability. The major weight loss is between 500 to $551^{\circ} \mathrm{C}$. TGA results have been supported by the DTA results. In DTA, there are exothermic peaks, the first transition hump at $527^{\circ} \mathrm{C}$ revealed the dehydration, adsorption and oxidation from the semi-crystalline host and the sharp major peak at $551^{\circ} \mathrm{C}$ signifies the irreversible dissociation of the crystallites whereas the small peak at $560^{\circ} \mathrm{C}$ may be due to fusion.

Table 2. The thermograms results of the TGA/DTA studies of the P-F resin.

\begin{tabular}{ccccccc}
\hline Sample & IDT & Wt. loss & FDT & Wt. loss & $\%$ Residue & DTA peaks ${ }^{\circ} \mathrm{C}(\mu \mathrm{V})$ \\
\hline PF resin & 500 & 26.61 & 600 & 72.41 & 0.16 & $\begin{array}{c}527(7.3), 551(14.4), \\
560(10.5)\end{array}$ \\
\hline
\end{tabular}

\section{Mechanical studies}

The MOR, MOE and SP have been shown in the Table 3 which clearly show the increase in the mechanical strength 8.40. When the P-F composite was tested for its hardness it was found to be brittle.

Table 3. The mechanical evaluation of the P-F composite

\begin{tabular}{cccc}
\hline Sample & $\begin{array}{c}\text { MOR } \\
\mathrm{N} / \mathrm{mm}^{2}\end{array}$ & $\begin{array}{c}\text { MOE } \\
\mathrm{N} / \mathrm{mm}^{2}\end{array}$ & $\begin{array}{c}\mathrm{SP} \\
\mathrm{N} / \mathrm{mm}^{2}\end{array}$ \\
\hline P-F composite & 43.20 & 496.12 & 38.40 \\
\hline
\end{tabular}

\section{Conclusion}

The phenol-formaldehyde resin has immense applications in the development of latest technologies and one of the best uses is to prepare the composites. These composites not only have better physico-chemical, mechanical and thermal properties for domestic and industrial application avenues but can further be improved by reinforcing them with natural fibers to incorporate high strength and avail better use of waste biomass 


\section{References}

1. Joel R Fried, Polymer Science \& Technology, $2^{\text {nd }}$ Ed., 2003, 382.

2. Bentsianova I Y, Veksler G M, Markov L R, Melamed S N and Petrienko P M, Derevoobrabatyrayushchaya Promyshlennost, 1962, 11, 9.

3. Joseph S, Sreekala M S, Oommen Z, Koshy P and Thomas S, Compos Sci Technol., 2002, 62, 1857.

4. Canche-Escamilla G, Cauich-Cupul J I, Mendizabal E, Puig J E, Vazquez-Torres H and Herrera-Franco P J, Composites Part A: Applied Science and Manufacturing, 1999, 30, 349.

5. Singha A S, Kumar S and Kaith B S, Int J Plast Tech., 2005, 9, 427.

6. Kaith B S, Singha A S, Dweivedi D K, Kumar S, Kumar D and Dhemeniya A, Int J Plast Tech., 2003, 7, 119.

7. Dweivedi D K, Singha A S, Kumar S and Kaith B S, Int J Plast Tech., 2004, 8, 299.

8. Susheel Kalia and Kaith B S, E J Chem., 2008, 5, 177.

9. Fred W and Billmeyer J R, Textbook of Polymer Science, 1994, 3, 438. 


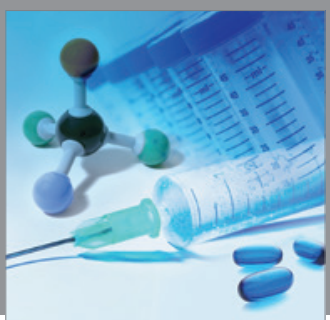

International Journal of

Medicinal Chemistry

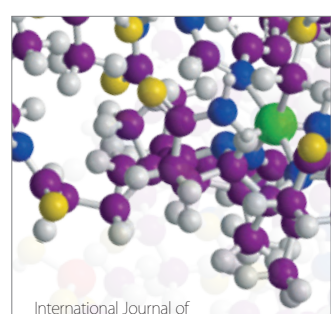

Carbohydrate Chemistry

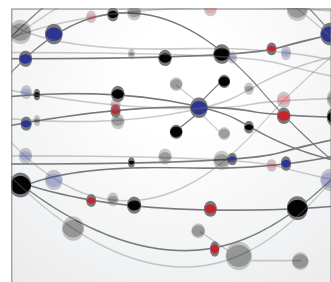

The Scientific World Journal
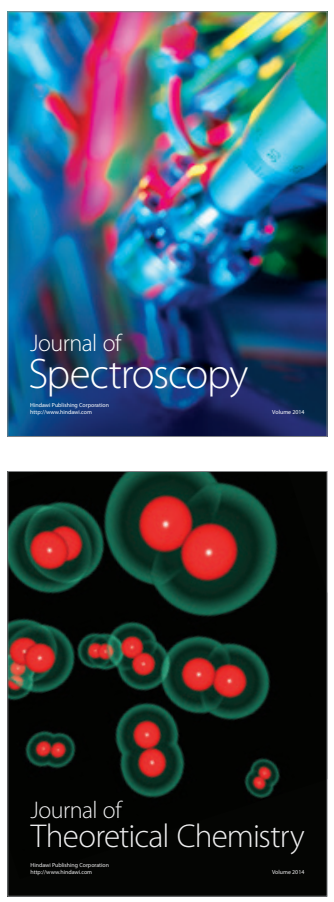
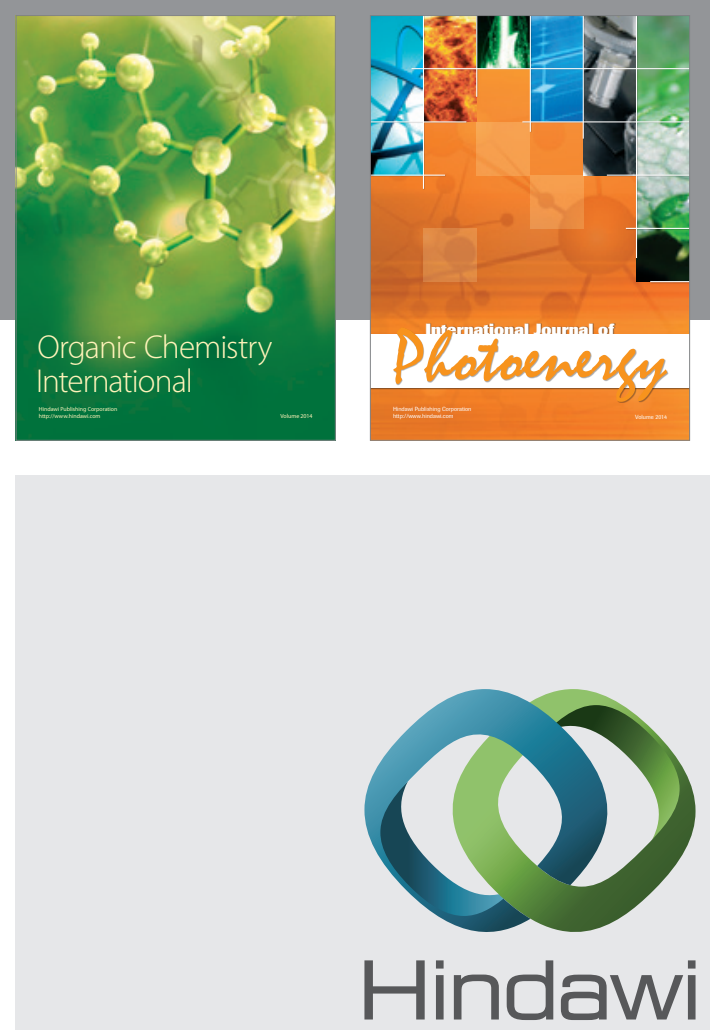

Submit your manuscripts at

http://www.hindawi.com
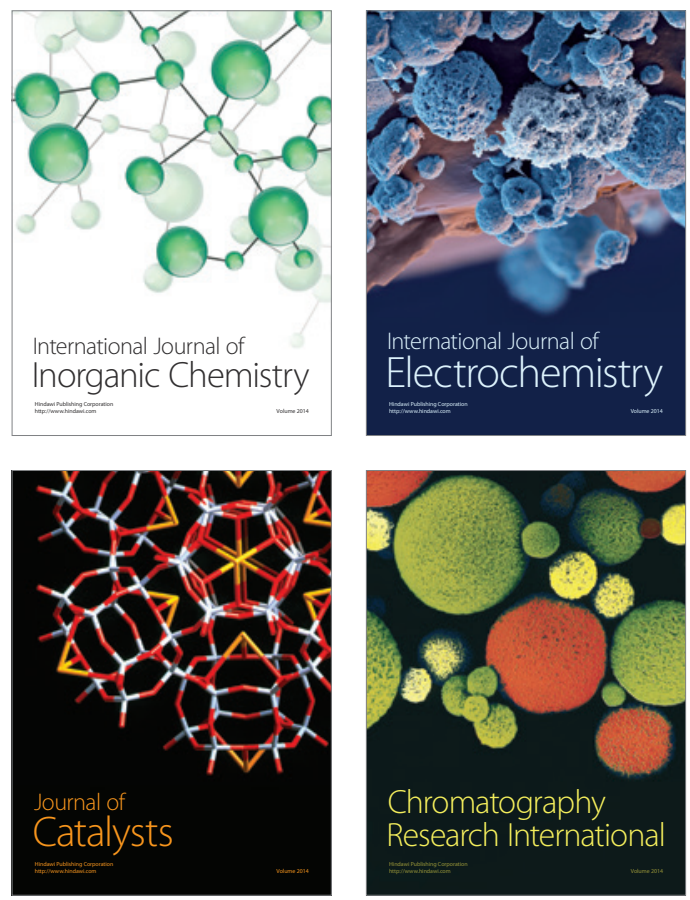
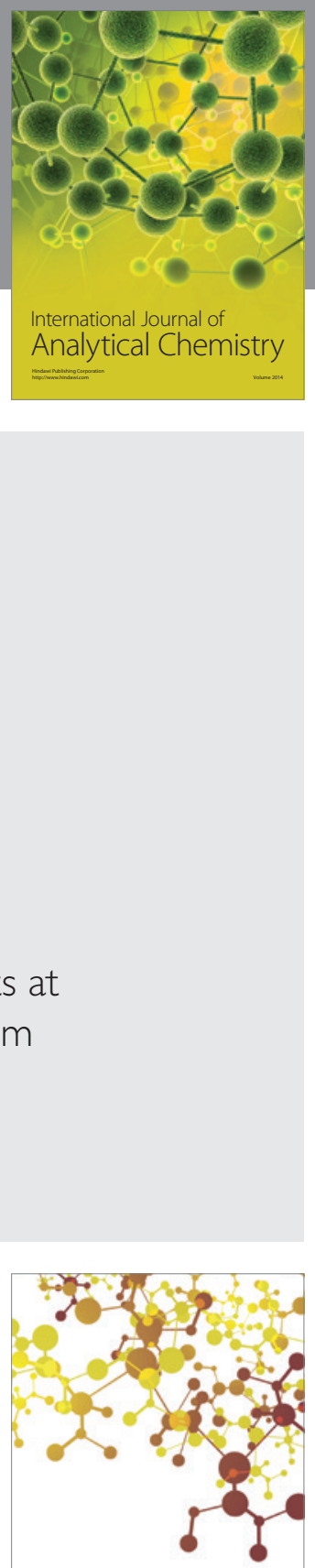

Journal of

Applied Chemistry
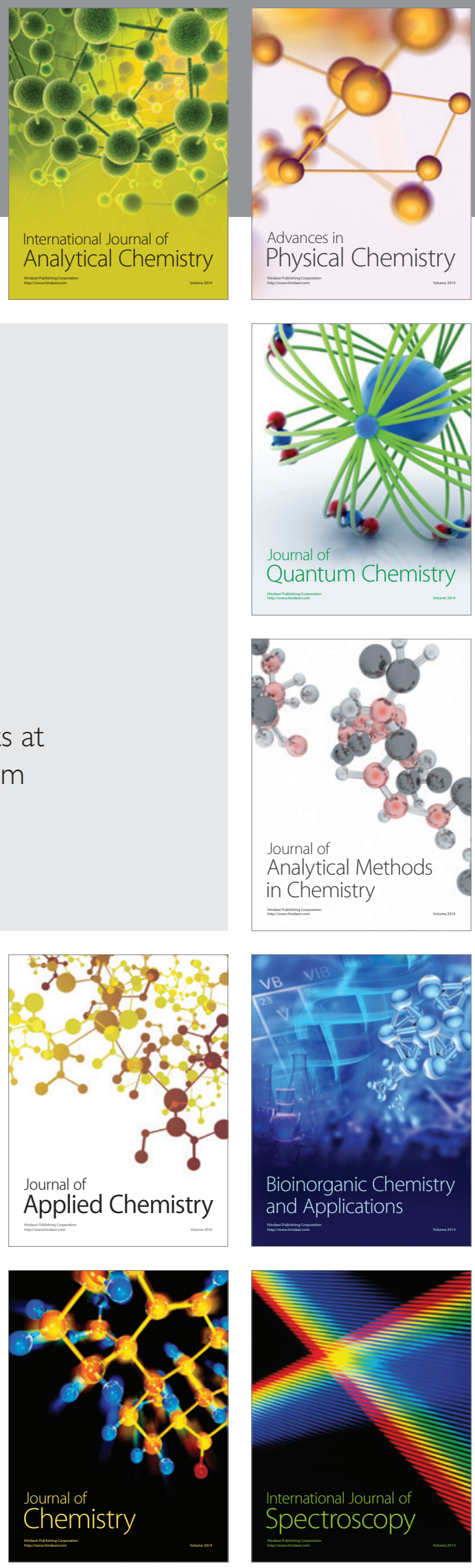